\title{
Impactos socioambientais provocados por um vazadouro a céu aberto: uma análise no distrito de Marudá/PA
}

Analisar os impactos socioambientais advindos da disposição final dos resíduos sólidos em um lixão céu aberto situado no distrito de Marudá/PA. A metodologia da pesquisa compreendeu: revisão da literatura, pesquisa de campo pela observação sistemática e aplicação de Check-list utilizando a matriz de Leopold de avaliação qualitativa dos impactos ambientais na área de estudo. Ademais, foram aplicados 30 questionários para as famílias que residem no entorno do lixão visando diagnosticar a percepção dos moradores sobre os possíveis riscos decorrentes da destinação final inadequada dos resíduos sólidos. Os dados foram analisados utilizando estatística não-paramétrica por intermédio do teste binomial que visa identificar a distribuição probabilística discreta das respostas obtidas nos formulários com utilização do software BioEstat. Os resultados apontaram a média de resíduos encaminhados ao vazadouro de 7.433 toneladas entre os anos de 2012 a 2016 registrados pelo SNIS e os impactos ambientais são diversos tais como: poluição do solo, do ar e dos recursos hídricos. Foi evidenciado ainda que, os moradores têm consciência da degradação ocasionada pelo vazadouro da cidade e dos riscos que essa forma de destinação final provoca ao meio ambiente em $100 \%(p=1.0)$, a população se sente marginalizada por residir próximo ao lixão $60 \%(p=0.61)$, e $100 \%(p=1.0)$, reclamam principalmente dos odores liberados pela decomposição dos resíduos, além da desvalorização dos imóveis em $90 \%$ dos casos $(p=0.91$ ); relataram ainda ter contraído doenças em $43 \%$ dos casos ( $p=0.46$ ) e $100 \%(p=1.0)$ da comunidade adotou medidas preventivas como forma de precaução a doenças.

Palavras-chave: Resíduos Sólidos; Lixão; Destinação Final.

\section{Socio-environmental impacts caused by an open sky leak: an analysis in the Marudá/PA district}

\begin{abstract}
To analyze the socioenvironmental impacts resulting from the final disposition of solid waste in an open pit located in the district of Marudá/PA. The research methodology included: literature review, field research by systematic observation and Check-list application using Leopold's matrix of qualitative assessment of environmental impacts in the study area. In addition, 30 questionnaires were applied to the families living in the vicinity of the dump, in order to diagnose the residents' perception of the possible risks resulting from the inadequate final disposal of solid waste. The data were analyzed using non-parametric statistics through the binomial test to identify the discrete probabilistic distribution of the answers obtained in the forms using BioEstat software. The results indicate the average of waste sent to the dump of 7,433 tons between the years 2012 to 2016 registered by the SNIS and the environmental impacts are diverse such as: pollution of soil, air and water resources. It was also evidenced that, residents are aware of the degradation caused by the city's dump and the risks that this form of final destination causes to the environment in $100 \%(p=1.0)$, the population feels marginalized because it resides near the dump $60 \%(p=0.61)$, and $100 \%(p=$ $1.0)$, complained mainly of the odors released by the decomposition of residues, in addition to the devaluation of real estate in $90 \%$ of cases $(p=0.91) ;(p=0.46)$ and $100 \%(p=1.0)$ of the community adopted preventive measures as a precautionary measure for diseases.
\end{abstract}

Keywords: Solid Waste; Dumping ground; Final Destination.

Topic: Engenharia Sanitária

Reviewed anonymously in the process of blind peer

Fábio Sergio Lima Brito (ib)

Universidade Federal do Pará, Brasi http://lattes.cnpq.br/6013840156333944

http://orcid.org/0000-0002-3807-0499

fabio.lima.ufpa@gmail.com

Bruna Andrade Pimentel (iD)

Universidade Federal do Pará, Brasil

http://lattes.cnpq.br/2519889447406937

http://orcid.org/0000-0002-6295-7487

bruna.and14@gmail.com

\section{Mateus Souza Morais (iD)}

Universidade Federal do Pará, Brasil

http://lattes.cnpq.br/5569244340023784

http://orcid.org/0000-0002-7348-2114

mateussmorais8@gmail.com

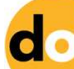

DOI: 10.6008/CBPC2179-6858.2019.005.0012
Received: 12/08/2019

Approved: 27/09/2019

Karla Karoline Leite do Rosário (it)

Universidade Federal do Pará, Brasil

http://lattes.cnpq.br/7554324212389148

http://orcid.org/0000-0001-8919-9201

karlaleite93@gmail.com

Rosa Helena Ribeiro Cruz (iD)

Universidade Federal Rural da Amazônia, Brasil

http://lattes.cnpq.br/9023057183800808

http://orcid.org/0000-0002-8347-1208

cruzrh@gmail.com
Referencing this:

BRITO, F. S. L.; PIMENTEL, B. A.; MORAIS, M. S.; ROSÁRIO, K. K. L.; CRUZ, R. H. R.. Impactos socioambientais provocados por um vazadouro a céu aberto: uma análise no distrito de Marudá/PA Revista Ibero Americana de Ciências Ambientais, v.10, n.5, p.128139, 2019. DOI: http://doi.org/10.6008/CBPC21796858.2019.005.0012 


\section{INTRODUÇÃO}

No século XIX, com o advento da Revolução Industrial houve a expansão do número de fábricas e produtos em todo mundo. Na contemporaneidade, o crescimento exacerbado do consumo está relacionado ao fenômeno da globalização e do crescimento das populações urbanas o que tem ocasionado grandes problemas à sociedade com o demasiado aumento da geração de resíduos sólidos (BRITO, 2015). No entanto, o planejamento na gestão e no gerenciamento de resíduos sólidos não acompanham esses avanços, fato que provoca inúmeros impactos ao meio ambiente. Nesse aspecto, a Política Nacional de Resíduos Sólidos (PNRS), no seu artigo $3^{\circ}$, inciso XVI, define os resíduos sólidos como:

Material, substância, objeto ou bem descartado resultante de atividades humanas em sociedade, a cuja destinação final se procede, se propõe proceder ou se está obrigado a proceder, nos estados sólido ou semissólido, bem como gases contidos em recipientes e líquidos cujas particularidades tornem inviável o seu lançamento na rede pública de esgotos ou em corpos d'água, ou exijam para isso soluções técnica ou economicamente inviável em face da melhor tecnologia disponível. (BRASIL, 2010)

Nessa perspectiva, Vaz et al. (2003) destacam que a poluição por resíduos sólidos pode ser caracterizada como qualquer alteração das características naturais de um ambiente. Braga (2015) ressalta ainda que, no meio ambiente o resíduo é visto como um 'invasor', já que a natureza segue um ciclo natural para decomposição dos refugos, mas com a produção e o consumo exagerados, a natureza fica incapacitada de absorver o excessivo número de materiais. Por consequência, os resultados são poluição hídrica, atmosférica e dos solos, e ainda a criação e/ou proliferação de vetores de doenças pela disposição inadequada dos resíduos.

No Brasil são 5.553 municípios com coleta de resíduos sólidos domiciliares e/ou públicos, o que confere um total de 183.488 toneladas dia e 78,4 milhões toneladas anuais, e a quantidade de resíduos recebidos é de 259.547 t/dia nos locais conferidos ao destino final dos resíduos sólidos (IBGE, 2008; IPEA, 2012). Então se percebe a necessidade de uma gestão adequada dos resíduos produzidos pela população, órgãos públicos e privados em todo o país.

Nessa perspectiva, a PNRS (2010) solicita que Estados e Municípios apresentem os Planos de Gestão Integrada de Resíduos Sólidos (PMGIRS) para que assim possam firmar convênios e acordos contratuais com a União para o repasse de verbas nos programas direcionados a efetivação da política. Conforme a PNRS os planos devem contemplar:

A situação atual dos resíduos sólidos, diagnóstico com impactos ambientais e econômicos e diretrizes para o manejo diferenciado, proposição de cenários, metas de redução, reaproveitamento e eliminação dos lixões, programas, projetos e ações para o atendimento das metas previstas, zonas favoráveis para a localização de áreas para destinação de resíduos e disposição final de rejeitos, programas de educação ambiental e comunicação social para o manejo de resíduos sólidos, controle e fiscalização de sua implementação e operacionalização, articulação entre órgãos da administração e estruturação da autoridade municipal para a implantação do PMGIRS. (BRASIL, 2010)

Conforme o IBGE (2008), apenas 33,5\% dos municípios (representando 1.865 municípios) declararam possuir PMGIRS nos termos estabelecidos pela PNRS. Nessa lógica, muitos municípios ainda possuem uma destinação final ambientalmente inadequada dos rejeitos o que provoca impactos ambientais, sociais e 
econômicos para toda a sociedade. Conforme a Associação Brasileira de Empresas de Limpeza Pública e Resíduos Especiais (ABRELPE, 2017), 3.352 dos municípios ainda continuam enviando mais de 29 milhões de toneladas de resíduos para lixões ou aterros controlados, o que corresponde a $41,6 \%$ dos resíduos coletado no Brasil.

Argolo (2013) destaca que são altos os gastos e investimentos envolvidos na implantação da gestão dos Resíduos Sólidos Urbanos (RSU), o que ocasiona total dependência dos municípios com relação aos recursos da União, o que pode impossibilitar a implementação da disposição final ambientalmente e sanitariamente adequada dos rejeitos. Nesse sentido, os entraves institucionais são ainda maiores em municípios de médio e pequeno porte para a inserção de aterros sanitários o que inviabiliza as diretrizes e metas estabelecidas pela PNRS, tornando-a mais um aparato legal sem aplicabilidade efetiva.

Nesse contexto, os lixões ou vazadouros a céu aberto são "formas inadequadas de destinação final de resíduos e rejeitos, que consiste na descarga do material no solo sem qualquer técnica ou medida de controle" (MMA, 2011). Desse modo, Lira (2009) alerta que esses locais são característicos pela contaminação que causam ao meio ambiente tais como: percolação dos líquidos derivados da putrefação do lixo, transmissão de doenças para animais e pessoas, liberação de gases poluentes para a atmosfera, além de riscos de incêndios causados pela geração de gases na decomposição dos resíduos provocando impactos ambientais. A resolução do Conselho Nacional de Meio Ambiente (CONAMA) $n^{\circ}$ 001/1986 dispõe o conceito de Impacto Ambiental que é exemplificado como:

Qualquer alteração das propriedades físicas, químicas e biológicas do meio ambiente, causada por qualquer forma de matéria ou energia resultante das atividades humanas que direta ou indiretamente afetam: a saúde, a segurança e o bem-estar da população; as atividades sociais e econômicas, a biota, as condições estéticas e sanitárias do meio ambiente; e a qualidade dos recursos ambientais. (CONAMA, 1986)

Além disso, os impactos provenientes dos lixões prejudicam não somente ao meio ambiente, mas também culminam em problemas sociais graves decorrentes da forma degradante de trabalhos em que os catadores de materiais recicláveis ficam expostos, bem como, a vulnerabilidade daqueles que moram no entorno do lixão devido as situações de riscos que podem alterar qualidade de vida da comunidade. Diante dessa problemática os estudos sobre a percepção vêm ganhando importância como uma das ferramentas fundamentais para a elaboração e execução das políticas públicas visando contribuir para melhoria da qualidade do ambiente e de vida da população (BARROS, 2015).

A percepção da população sobre as problemáticas ambientais e de saúde pública, são imprescindíveis para um melhor conhecimento dos espaços nos quais estão inseridos. O valor atribuído aos territórios, e como as comunidades enxergam as condições ambientais e de vida no momento histórico em que vivem, são ferramentas indispensáveis para a elaboração de um diagnóstico situacional e de um futuro planejamento (COSTA, 2011).

Portanto, este trabalho teve por objetivo analisar qualitativamente os impactos ambientais no meio físico, biótico e antrópico decorrente da destinação final dos resíduos sólidos no distrito de Marudá/PA, bem como, identificar as consequências negativas na vida da população limítrofe ao lixão com enfoque nos aspectos sociais e de saúde pública. 


\section{METODOLOGIA}

\section{Área de estudo}

O estudo foi desenvolvido no distrito de Marudá localizado no litoral do Município de Marapanim instituído em 1914, pela Lei no 1.464, de 31 de agosto. Localiza-se na mesorregião do nordeste paraense, microrregião Salgado e dista cerca de $142 \mathrm{~km}$ da capital Belém. O lixão da cidade ocupa uma área de aproximadamente $1.200 \mathrm{~m}^{2}$, situa-se nas seguintes coordenadas geográficas: latitude de 0³7'59.59"S e longitude $47^{\circ} 39^{\prime} 15.30 " \mathrm{O}$ (Figura 1 ).

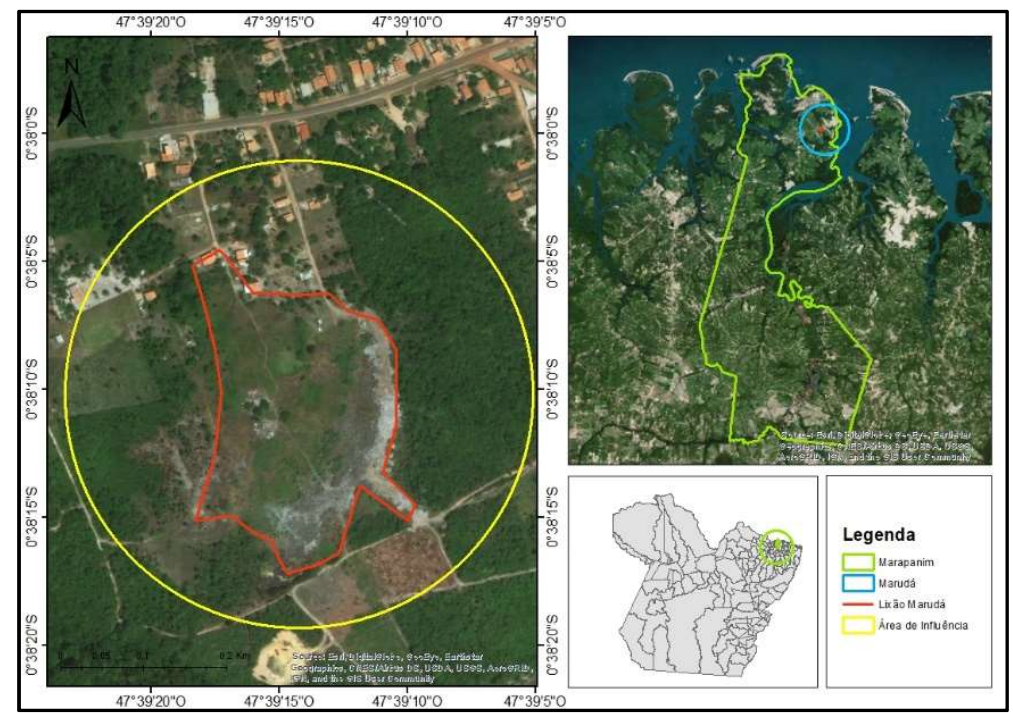

Figura 1: Localização do vazadouro a céu aberto de Marudá/PA.

\section{Pesquisa de Campo}

A pesquisa de campo que subsidiou a avaliação qualitativa dos impactos ambientais do vazadouro a céu aberto do distrito de Marudá, foi mediante a observação sistemática e posteriormente aplicação de Check-list da matriz de Leopold et al. (1971) em que é possível identificar e listar as relações de ação, causas e consequências dos possíveis impactos.

\section{Coleta de dados}

Os dados foram obtidos por intermédio da abordagem quanti-qualitativa, por meio de um questionário dicotômico estruturado com perguntas fechadas aplicado a 30 (trinta) famílias que residem no perímetro limítrofe ao lixão. Dentre as perguntas desatacaram-se: perfil dos moradores, tempo de moradia, aspectos ambientais e sociais, percepção de risco e de saúde pública. As entrevistas foram adaptadas dos procedimentos de Gomes et al. (2015) aprovado pelo comitê de ética (Parecer 179.024/2012).

\section{Análise dos dados}

Posteriormente a coleta realizou-se a análise dos dados mediante a aplicação da estatística não paramétrica utilizando o teste binomial com o auxílio do software BioEstat e tabulação de gráficos para melhor visualização. Por fim, organizou-se as informações com base na construção da explicação, que 
segundo Yin (2001) o foco é analisar os dados construindo uma explanação sobre a realidade estudada.

\section{RESULTADOS E DISCUSSÃO}

\section{Destinação Final}

Na tabela 1 são apresentados os dados referentes a quantidade de resíduos sólidos coletados e encaminhados ao vazadouro da cidade de Marudá registrados pelo Sistema Nacional de Informações sobre Saneamento (SNIS), em que é possível perceber que a média foi de 7.433 toneladas/ano e a maior quantidade disposta foi no ano de 2016 e a menor em 2012 e nos demais anos não houve variações.

Um dos possíveis motivos para que a quantidade de resíduos tenha sido a mesma nos de 2013, 2014 e 2015 pode estar relacionado a falta de controle das cargas despejadas no lixão o que levou a prefeitura da cidade a fornecer dados duvidosos ao SNIS, visto que, o órgão administra e organiza as informações concedidas pelas prestadoras do serviço, mas não fiscaliza a veracidade dos dados.

Tabela 1: Quantidade de resíduos sólidos dispostos no lixão de Marudá 2012 a 2016.

\begin{tabular}{|l|l|}
\hline Ano & Quantidade em toneladas \\
\hline 2016 & $17.552,0$ \\
\hline 2015 & $5.900,0$ \\
\hline 2014 & $5.900,0$ \\
\hline 2013 & $5.900,0$ \\
\hline 2012 & $1.913,7$ \\
\hline
\end{tabular}

Na tabela 2 estão dispostos os resultados referente a visita in loco realizada no lixão a céu aberto do distrito de Marudá, na qual foi possível observar que todos os resíduos gerados na cidade e nos demais distritos (Matapiquara e Monte Alegre do Maú) são destinados ao vazadouro, o qual recebe todos os tipos de resíduos sendo eles: domiciliares, de construção civil, limpeza pública, podas, eletrônicos e de serviço de saúde (Figura 2-a).

O caminhão da prefeitura descarrega os resíduos em média 3 vezes na semana o que corresponde aos dias em que é realizada a coleta domiciliar na cidade. Os resíduos sólidos são descartados diretamente no solo em forma de pilhas, sem compactação ou aterramento e não é realizado controle sobre origem, classificação ou periculosidade. Segundo Araújo (2015) essa prática aumenta os processos erosivos, altera a capacidade de uso da terra com danos ao relevo e vegetação, provocando a redução da biota e, consequentemente, ocasiona a poluição do solo (Figura 2-b).

Para Bendito et al. (2017), a contaminação do solo em áreas de destinação sanitariamente incorreta é proveniente dos diversos resíduos despejados nesses locais dentre eles: resíduos domiciliares que geram o chorume no processo de decomposição da matéria orgânica, os resíduos eletroeletrônicos que apresentam em sua composição metais pesados (chumbo, mercúrio, cádmio e zinco) e dos resíduos de serviço de saúde na geração de vetores e contaminação do lençol freático. Além disso, o vazadouro não apresenta isolamento em sua extensão territorial, por conseguinte, a área é de livre acesso, uma vez que, não existem guarnições para controlar possíveis descargas sem procedência. Com isso, foi observado o despejo irregular de resíduos sólidos por pessoas não autorizadas no local. 
Nesse sentido, foi constatado que os resíduos são queimados visando a diminuição do volume depositado no local, sendo essa prática comum, principalmente dos resíduos de serviços de saúde (Figura 2c). No processo de decomposição dos RSU ocorre a produção de gases como metano $\left(\mathrm{CH}_{4}\right)$, óxido de enxofre $\left(\mathrm{SO}_{3}\right)$, gás carbônico $\left(\mathrm{CO}_{2}\right)$, nitrogênio $\left(\mathrm{N}_{2}\right)$ e material particulado sendo liberado para atmosfera, além de gases tóxicos para os diversos organismos (CAIXETA, 2005; MARQUES, 2011).

Tabela 2: Matriz de avaliação qualitativa dos impactos ambientais do lixão a céu aberto de Marudá/PA.

\begin{tabular}{|c|c|c|c|c|c|c|c|c|c|c|c|c|c|}
\hline \multirow{3}{*}{ Impactos Ambientais } & \multicolumn{13}{|c|}{ Características } \\
\hline & \multicolumn{3}{|c|}{ Frequência } & \multicolumn{2}{|c|}{ Extensão } & \multicolumn{3}{|c|}{ Duração } & \multicolumn{2}{|c|}{ Sentido } & \multicolumn{3}{|c|}{ Grau de Impacto } \\
\hline & $\mathbf{T}$ & $\mathrm{Pr}$ & $\mathbf{C}$ & $\mathbf{L}$ & $\mathbf{R g}$ & $\mathrm{Cp}$ & $\mathrm{Mp}$ & Lp & $\mathbf{P}$ & $\mathbf{N}$ & B & $\mathbf{M}$ & A \\
\hline & \multicolumn{13}{|c|}{ Meio Físico } \\
\hline Aumento dos processos erosivos & & & $x$ & $\mathrm{x}$ & & & $\mathrm{x}$ & & & $\mathrm{x}$ & & & $\mathrm{x}$ \\
\hline Compactação do solo & & & $x$ & $x$ & & & $x$ & & & $\mathrm{x}$ & & $x$ & \\
\hline Emissão de gases de efeito estufa & $\mathrm{x}$ & & & $\mathrm{x}$ & & & & & & $\mathrm{x}$ & & $\mathrm{x}$ & \\
\hline Possível contaminação do solo & & & $\mathrm{x}$ & $\mathrm{x}$ & & & $\mathrm{x}$ & & & $\mathrm{x}$ & & & $\mathrm{x}$ \\
\hline \multirow[t]{2}{*}{ Possível depreciação do lençol freático } & & & $x$ & $\mathrm{x}$ & & & & & & $x$ & & & $x$ \\
\hline & \multicolumn{13}{|c|}{ Meio Biótico } \\
\hline Stress da fauna local & $x$ & & & $\mathrm{x}$ & & & $x$ & & & $\mathrm{x}$ & & $x$ & \\
\hline Redução da biodiversidade nativa & & & $x$ & $x$ & & & $x$ & & & $x$ & & $x$ & \\
\hline Redução da capacidade de sustentação da flora & $\mathrm{x}$ & & & $\mathrm{x}$ & & & $\mathrm{x}$ & & & $\mathrm{x}$ & & $\mathrm{x}$ & \\
\hline \multirow[t]{2}{*}{ Redução da biota do solo } & & & $\mathrm{x}$ & $\mathrm{x}$ & & & & & & $\mathrm{x}$ & & $x$ & \\
\hline & \multicolumn{13}{|c|}{ Meio Antrópico } \\
\hline Poluição visual & & $x$ & & $\mathrm{x}$ & & & & $\mathrm{x}$ & & $\mathrm{x}$ & & & $\mathrm{x}$ \\
\hline Proliferação de doenças & & & $\mathrm{x}$ & $\mathrm{x}$ & & & & $\mathrm{x}$ & & $x$ & & & $x$ \\
\hline
\end{tabular}

*T- Temporário; Pr- Permanente; C- Cíclico; L- Local; Rg- Regional; Cp-Curto prazo; Mp- Médio prazo; Lp- Longo prazo; P- Positivo; B- Baixo; M- Médio; A- Alto. Fonte: Leopold et al. (1971).

Nesse contexto, foram identificados no meio físico alterações cíclicas que são recorrentes neste tipo de destinação final dos resíduos sólidos, impactos a nível local que alteram a qualidade do ar, água e solo e que tem duração de médio a longo prazo, podendo levar anos para a recuperação completa do meio. Com isso o sentido é negativo sendo de alto impacto devido aos déficits ao âmbito ambiental.

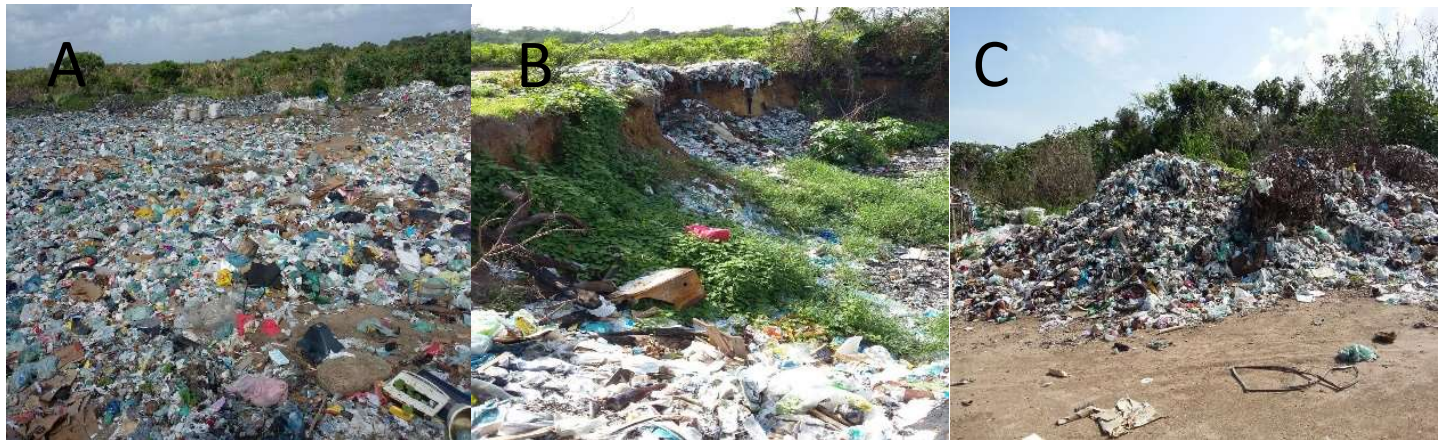

Figura 2: A) Resíduos Misturados; B) Erosão do solo; C) Queima dos Resíduos.

No meio biótico foi verificado o stress da fauna, redução da biota, compactação do solo devido da passagem de veículos pesados e provável alteração da biodiversidade nativa do local. Além disso, não existe monitoramento superficial dos mananciais próximos ao lixão, o que seria extremamente importante para avaliar os possíveis impactos ambientais, pois foi evidenciada uma lagoa de chorume no lixão (Figura 3-a).

A depreciação do lençol freático é ocasionada principalmente em decorrência da ausência da impermeabilização tornando inevitável a contaminação das águas subterrâneas em virtude da percolação do chorume (ATHAYDE JÚNIOR et al., 2009). Os corpos hídricos limítrofes aos lixões apresentam grande 
potencial de contaminação pelo escoamento superficial das águas no período chuvoso (ISMAEL, 2013).

Ademais, em áreas características como os vazadouros a céu aberto são evidenciados os macros vetores, como moscas, baratas, ratos, cachorros e urubus (figura 3-b), como também micro vetores, bactérias, fungos e vírus os quais são responsáveis pela transmissão de inúmeras doenças, por exemplo: leptospirose, diarreia, dengue e febre tifoide (PEREIRA et al., 2008).

Outro perigo iminente está nas plantações que os moradores do entorno do lixão cultivam como é o caso de uma moradora, a qual tem melancias em seu quintal e consome juntamente com a família, não sabendo da possível contaminação do alimento devido à proximidade com lixão (Figura 3-c). Assim como o risco de "bioacumulação pelo aumento da concentração de substância química no organismo, em relação a sua concentração presente no meio" (BENDITO et al., 2017).

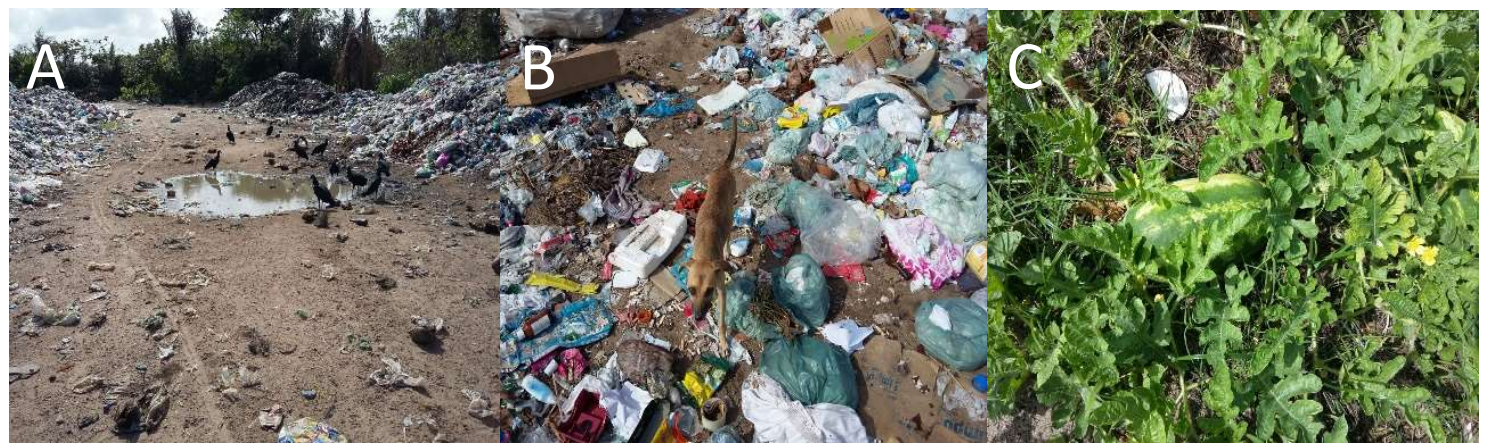

Figura 3: A) Lagoa de chorume; B) Animal de estimação; C) Cultivo de melancia por moradores que residem próximo ao vazadouro.

Quanto ao meio antrópico observou-se a poluição visual devido a área do lixão ser aberta, a força do vento leva os resíduos mais leves como plásticos e papéis para locais mais distantes ocasionando a alteração da paisagem natural e incômodos para os moradores do entorno (Figura 4-a). Foi observado ainda a presença de catadores de materiais recicláveis que buscam na catação meios de subsistência para manter a família (figura 4-b), "mesmo sendo uma forma de trabalho que garante a sobrevivência de milhares de indivíduos fora dos modelos convencionais de emprego e geração de renda estabelecidos pela sociedade capitalista, isso só é possível porque a sociedade gera grandes quantidades de resíduos e estes precisam ser coletados" (ONE et al., 2011).

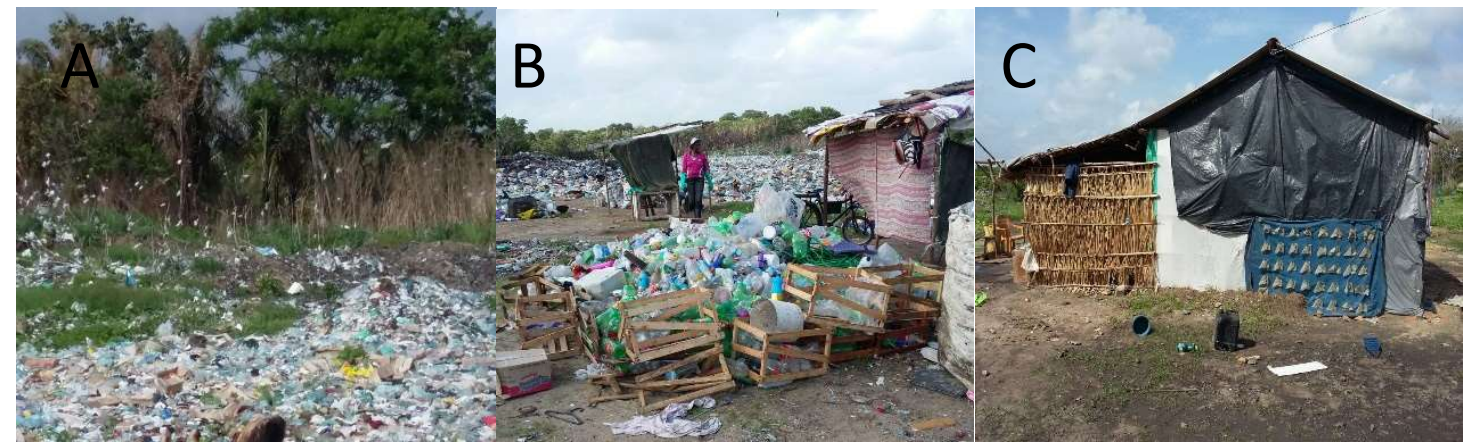

Figura 4: A) Resíduos em árvores; B) Catadora de materiais recicláveis; C) Residência de catadores dentro do lixão.

Vale ressaltar que, alguns catadores residem também dentro do lixão em barracas improvisadas e, consequentemente, em péssimas condições higiênico-sanitárias e de salubridade (Figura 4-c). No manejo dos 
resíduos sólidos os riscos relacionados à saúde pública dos trabalhadores decorrem de uma série de fatores que incluem desde os aspectos ambientais e ocupacionais até os de consumo, dentre as outras formas de perigo devido ao contato com objetos e utensílios contaminados, tais como: produtos químicos, materiais perfurocortantes, animais mortos e resíduos de serviço de saúde (CAVALCANTE, 2007; SIQUEIRA et al., 2009).

\section{Diagnóstico das representações ambientais, sociais e de saúde pública}

Com a aplicação dos questionários no local em que houve a pesquisa, observou-se que $100 \%$ da população que reside próximo ao vazadouro a céu aberto tem percepção dos riscos ambientais que esta forma incorreta de destinação final dos resíduos pode ocasionar, em que foram citados pelos habitantes poluição do ar, solo e principalmente da água, visto que, a maior parte da população consome água de manancial subterrâneo, por isso a grande preocupação por parte dos moradores. Ao analisar estatisticamente os dados $(p=1.0)$ o que significar dizer que a proporção observada não é significativamente diferente da proporção esperada (Figura 5-a).

Quando perguntados se os moradores se sentiam diferentes dos demais cidadãos da cidade por residirem próximo ao lixão, $40 \%$ não se sentem discriminados enquanto que $60 \%$ dos moradores demonstraram insatisfação relacionado a algum aspecto social. Ao observar o valor de $(p=0.61)$ pode-se dizer que a proporção observada não é significativamente diferente da proporção esperada sendo então comprovada a relação estatística (Figura 5-b). Nesse sentido se destacam as falas de dois habitantes que denunciam situações de discriminação, preconceito e insegurança que as famílias sofrem:

Eu me sinto mal, as pessoas têm muito preconceito, acham que a gente é porco porque vive perto do lixo, eu vou passando na rua e as pessoas gritam lá vem a Maria do lixão, fico com raiva não moro no lixão, moro perto, não tenho culpa né mano, minhas coisas são tudo limpinhas pode olhar.

Assim é meio ruim, porque aqui passa muita gente tanto do bem como do mal, tem o pessoal que trabalha aí no lixão, mas tem gente que vai só fazer o que não presta, roubar, fumar, eu tenho medo as vezes e nem passa polícia aqui, a gente somos esquecidos.

Diante do exposto no discurso dos residentes do entorno do lixão a céu aberto fica claro que a destinação irregular dos resíduos sólidos ocasiona prejuízos não somente ao meio ambiente, mas impacta diretamente na questão social, principalmente da população com vulnerabilidade socioeconômica.
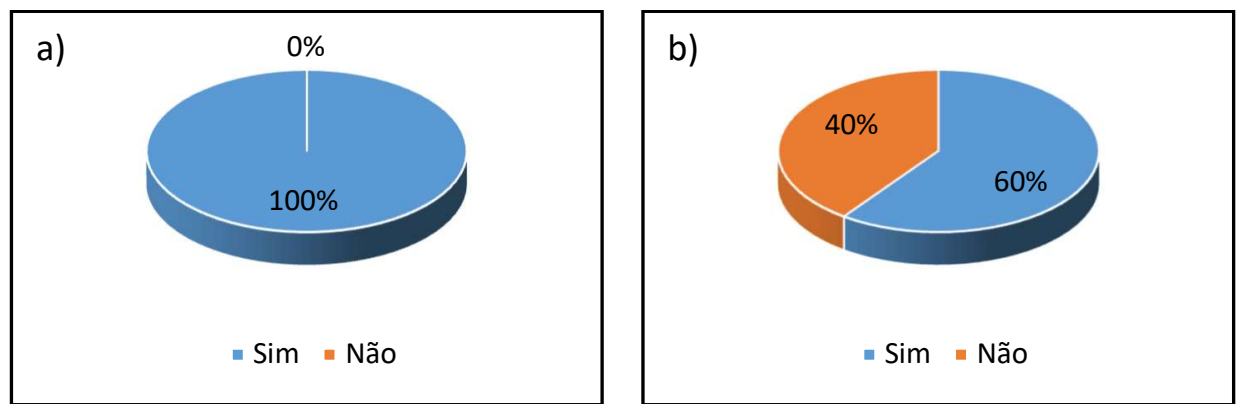

Figura 5: A) Percepção dos moradores sobre os riscos ambientais; B) Percepção de risco dos aspectos sociais.

Quando perguntados sobre possíveis desconfortos ocasionados pela proximidade com o vazadouro, $100 \%$ dos entrevistados se mostraram incomodados, isso porque são diversos os problemas advindos da destinação final dos resíduos de forma incorreta. Como consequência a população sofre com os fortes odores 
diariamente, proliferação de moscas e demais mosquitos causadores de doenças, além da fumaça proveniente da queima do lixo em alguns dias da semana. Os dados $(p=1.0)$ o que significa dizer que há relação estatística entre as variáveis perguntadas no questionário (Figura 6-a).

Outro aspecto analisado foi em relação a desvalorização dos imóveis, em que $90 \%$ dos habitantes se sentem prejudicados, pois não conseguem vender as residências tampouco trocar por outro lugar mais confortável e $10 \%$ não sentem lesados, pois não pensam em mudar de residência mesmo com os problemas recorrentes do local (Figura 6-b).

Segundo Faria (2002) para evitar a poluição visual e a desvalorização das propriedades da redondeza, é necessário que se faça o isolamento visual em casos de aterro sanitários. No entanto, os lixões a céu aberto não são locais planejados e não dispõem infraestrutura para que se evite problemas sociais, econômicos e ambientais. A estatística mostrou que $(p=0.91)$ demostrando relação causal entre as variáveis.
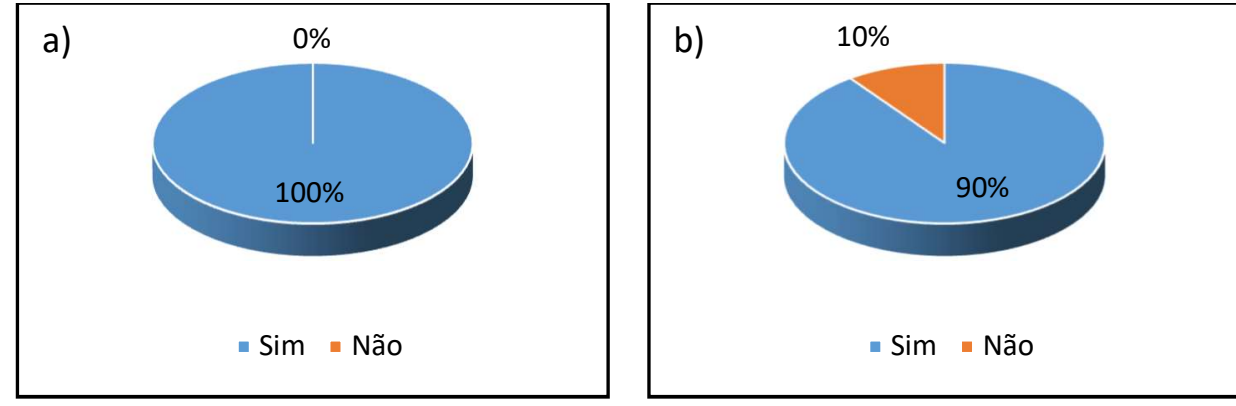

Figura 6: A) Percepção dos moradores sobre os desconfortos ocasionados pelo vazadouro; B) Moradores que percebem a desvalorização dos imóveis por morar próximo ao lixão.

No que diz respeito às doenças contraídas pela disposição dos resíduos, $43 \%$ dos moradores afirmaram já ter obtido patologias tais como: diarreia, verminoses, micoses e dengue demonstrando assim o risco que a população sofre devido à proximidade com o vazadouro e $57 \%$ dos entrevistados não contraíram doenças relacionadas a problemas com lixo (Figura 7-a).

De acordo com o Ministério da Saúde de 2007 a 2012 foram 217 casos de dengue e 60 suspeitas no município de Marapanim. Dessa forma, tais estatísticas corroboram para o que as pesquisas do Instituto Trata Brasil apontam, em que as áreas da região Norte têm as piores condições de saneamento básico do Brasil e com agravos à saúde da população. A análise estatística mostrou $(p=0.46)$ baixa associação entre as variáveis.

Por fim, quando questionados se a família adotou alguma medida preventiva após o acontecimento do surgimento de doenças, $100 \%$ dos moradores relataram manter a casa limpa para não atrair vetores, além de uso de pesticida durante a noite e uso de telas nas portas e janelas dos domicílios. Outra medida citada foi a limpeza dos terrenos, manutenção das tubulações nas residências para escoar corretamente as águas pluviais visando se resguardar de possíveis empoçamentos e limpeza das ruas para evitar a proliferação de vetores (Figura 7-b).

O fato de os moradores adotarem medidas de prevenção está fortemente ligada as informações recebidas por agentes de saúde que realizam visitas esporádicas nas residências, além dos postos de saúde próximos e escolas das redondezas que se preocupam com a de saúde pública da população. Os dados ( $p=$ 
1.0) o que significa dizer que há relação estatística entre as variáveis perguntadas no questionário.
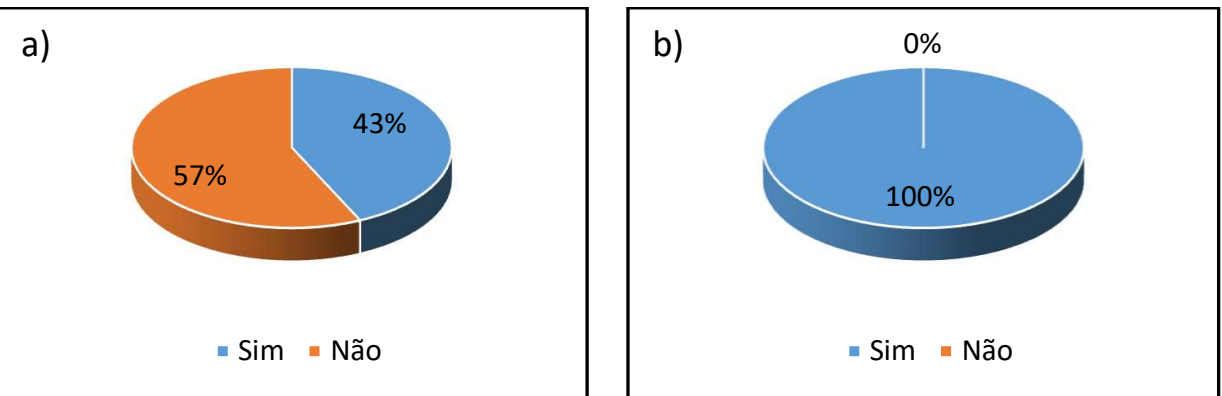

Figura 7: A) Doenças contraídas pelos moradores; B) Moradores que adotaram medidas preventivas.

\section{Marco Legal da Proibição dos Lixões no Brasil}

De modo geral, pode-se dizer que a destinação final de resíduos sólidos em lixões a céu abertos sempre foi proibida no Brasil mesmo que de forma indireta, pois a constituição de 1988 instituiu que o meio ambiente ecologicamente equilibrado é um direito irrevogável a todos os cidadãos. Nesse aspecto, a Política Nacional de Meio Ambiente (PNMA) tem como primícias em seu o art. $\mathrm{n}^{\circ} 2$ a preservação, melhoria e recuperação da qualidade ambiental. Para tanto, a Lei supracitada aponta o meio ambiente como um patrimônio público a ser garantido e protegido para o uso da coletividade (Tabela 3).

Indubitavelmente, a Lei de Crimes Ambientais trouxe significativos avanços, pois ela determina as sanções penais e administrativas decorrentes de condutas e atividades lesivas para o meio ambiente. Na referida Lei são definidas com clareza a uniformização das infrações da degradação e as punições para poluição do meio ambiente. Logo, sabe-se que o lixão é uma atividade potencialmente poluidora em que é possível perceber que não há conformidade a com as regulamentações vigentes do país.

Ainda nesse pensamento, a Lei de Saneamento Básico também traz contribuições importantes para a discussão dos resíduos sólidos, pois além de definir as etapas de gerenciamento dos RSU, é a primeira legislação que aborda a questão do tratamento dentro do contexto específico dos RSU apontando os municípios como responsáveis pela elaboração e construção do Plano Diretor Municipal (PDM) em que são definidas as diretrizes para o adequado planejamento e a implantação dentro do cenário do desenvolvimento urbano.

Por fim, a promulgação da PNRS em 2010 consolida a primeira Lei no Brasil específica para todos os resíduos gerados no país, exceto os radioativos. Embora a lei não trate de forma exclusiva do encerramento dos lixões, ela aborda a disposição final ambientalmente adequada dos rejeitos em aterros sanitários, sendo esta uma consequência para a eliminação e recuperação dos lixões a céu aberto nos PMGIRS.

Desse modo, levando em consideração o arcabouço legal e institucional do país, é possível afirmar que o vazadouro do distrito de Marudá/PA, assim como, toda e qualquer outra forma de destinação final sanitariamente inadequada dos resíduos sólidos configura-se como um crime ambiental legítimo com agravos nos âmbitos ambientais, sociais e econômicos, necessitando assim de medidas mitigadoras e corretivas em caráter de urgência a curto, médio e longo prazo. 
Tabela 3: Leis que abordam a temática de forma direta ou indireta da proibição dos lixões no Brasil.

\begin{tabular}{|c|c|c|}
\hline $\begin{array}{l}\text { Constituição do } \\
\text { Senado Federal de } \\
1988\end{array}$ & $\begin{array}{l}\text { Texto constitucional promulgado em } 5 \text { de outubro } \\
\text { de } 1988 \text {, com as alterações determinadas pelas } \\
\text { Emendas Constitucionais de Revisão nos } 1 \text { a } 6 / 94 \text {, } \\
\text { pelas Emendas Constitucionais nos } 1 / 92 \text { a } 91 / 2016 \\
\text { e pelo Decreto Legislativo no } 186 / 2008 \text {. }\end{array}$ & $\begin{array}{l}\text { Art. 225- Todos têm direito ao meio ambiente } \\
\text { ecologicamente equilibrado, bem de uso comum do } \\
\text { povo e essencial à sadia qualidade de vida, impondo- } \\
\text { se ao Poder Público e à coletividade o dever de } \\
\text { defendê-lo e preservá-lo para as presentes e futuras } \\
\text { gerações; }\end{array}$ \\
\hline $\begin{array}{l}\text { Política Nacional } \\
\text { de Meio Ambiente } \\
\text { de } n^{\circ} 6.938 \text { de } \\
1981\end{array}$ & $\begin{array}{l}\text { Dispõe sobre a Política Nacional do Meio } \\
\text { Ambiente, seus fins e mecanismos de formulação e } \\
\text { aplicação, e dá outras providências. }\end{array}$ & $\begin{array}{l}\text { Art. } 3 \text { o, inciso II - poluição, a degradação da qualidade } \\
\text { ambiental resultante de atividades que direta ou } \\
\text { indiretamente: } \\
\text { a) prejudiquem a saúde, a segurança e o bem-estar da } \\
\text { população; } \\
\text { b) criem condições adversas às atividades sociais e } \\
\text { econômicas; } \\
\text { c) afetem desfavoravelmente a biota; } \\
\text { d) afetem as condições estéticas ou sanitárias do } \\
\text { meio ambiente; } \\
\text { e) lancem matérias ou energia em desacordo com os } \\
\text { padrões ambientais estabelecidos; }\end{array}$ \\
\hline $\begin{array}{l}\text { Lei de Crimes } \\
\text { Ambientais } n^{\circ} \\
9.605 \text { de } 1988\end{array}$ & $\begin{array}{l}\text { Dispõe sobre as sanções penais e administrativas } \\
\text { derivadas de condutas e atividades lesivas ao meio } \\
\text { ambiente, e dá outras providências. }\end{array}$ & $\begin{array}{l}\text { Art. 54- Causar poluição de qualquer natureza em } \\
\text { níveis tais que resultem ou possam resultar em danos } \\
\text { à saúde humana, ou que provoquem a mortandade } \\
\text { de animais ou a destruição significativa da flora; }\end{array}$ \\
\hline $\begin{array}{l}\text { Política Nacional } \\
\text { de Saneamento } \\
\text { Básico } n^{\circ} 11.445 \\
\text { de } 2007\end{array}$ & $\begin{array}{l}\text { Estabelece diretrizes nacionais para o saneamento } \\
\text { básico; altera as Leis nos } 6.766 \text {, de } 19 \text { de dezembro } \\
\text { de } 1979,8.036 \text {, de } 11 \text { de maio de } 1990,8.666 \text {, de } \\
21 \text { de junho de } 1993,8.987 \text {, de } 13 \text { de fevereiro de } \\
\text { 1995; revoga a Lei no } 6.528 \text {, de } 11 \text { de maio de } 1978 \text {; } \\
\text { e dá outras providências. }\end{array}$ & $\begin{array}{l}\text { Art. 3. c) limpeza urbana e manejo de resíduos } \\
\text { sólidos: conjunto de atividades, infraestruturas e } \\
\text { instalações operacionais de coleta, transporte, } \\
\text { transbordo, tratamento e destino final do lixo } \\
\text { doméstico e do lixo originário da varrição e limpeza } \\
\text { de logradouros e vias públicas; }\end{array}$ \\
\hline $\begin{array}{lr}\text { Política } & \text { Nacional } \\
\text { de } & \text { Resíduos } \\
\text { Sólidos } & n^{\circ} 12.305 \\
\text { de } 2010 & \end{array}$ & $\begin{array}{l}\text { Institui a Política Nacional de Resíduos Sólidos; } \\
\text { altera a Lei no } 9.605 \text {, de } 12 \text { de fevereiro de 1998; e } \\
\text { dá outras providências. }\end{array}$ & $\begin{array}{l}\text { Art. 3. VIII - disposição final ambientalmente } \\
\text { adequada: distribuição ordenada de rejeitos em } \\
\text { aterros, observando normas operacionais específicas } \\
\text { de modo a evitar danos ou riscos à saúde pública e à } \\
\text { segurança e a minimizar os impactos ambientais } \\
\text { adversos; } \\
\text { Art. 15. V- metas para a eliminação e recuperação de } \\
\text { lixões, associadas à inclusão social e à emancipação } \\
\text { econômica de catadores de materiais reutilizáveis e } \\
\text { recicláveis; }\end{array}$ \\
\hline
\end{tabular}

Fonte: Adaptados de BRASIL (1988; 1981; 2007; 2010).

\section{CONCLUSÕES}

A disposição final dos resíduos sólidos no distrito de Marudá/PA é realizada de forma inadequada, gerando diversos problemas ambientais tais como: poluição do solo, ar e dos recursos hídricos e redução da biodiversidade nativa local. Ademais, foi constatado no meio físico, biótico e antrópico, diversas alterações como compactação do solo, proliferação de micro e macro vetores, redução da biota do solo e riscos de adoecimento devido a exposição do trabalho dos catadores no lixão.

Com relação aos moradores do entorno do vazadouro, muitos percebem os riscos que essa forma de destinação dos resíduos ocasiona tanto para o meio ambiente quanto para a população, pois eles percebem os problemas sociais e de saúde que os cercam como discriminação, preconceito e possíveis doenças veiculadas pelos resíduos como foram mencionadas nos questionários e ratificadas nas informações do Ministério da Saúde sobre o município. Portanto, observa-se a total falta de comprometimento do poder público municipal em dispor corretamente os resíduos e mostra também o descumprimento legal desde a Constituição Federal até a PNRS que obriga os órgãos a se adequarem com a elaboração do PMGIRS e instalação de aterros sanitários prevendo o fim dos lixões. 


\section{REFERÊNCIAS}

ABRELPE. Associação Brasileira de Empresas de Limpeza Pública e Resíduos Especiais. Panorama dos Resíduos Sólidos no Brasil. São Paulo: ABRELPE, 2017.

ARGOLO, J. C. R.. Sobre viver no/do lixo: o trabalho do catador de materiais recicláveis no aterro controlado do município de Amargosa/BA. Dissertação (Mestrado em Ciências Agrárias Ambientais e Biológicas) - Universidade Federal do Recôncavo da Bahia, Cruz das Almas, 2013.

ATHAYDE JÚNIOR, G. B.; NÓBREGA, C. C.; GADELHA, C. L. M.; SOUZA, I. M. F.; FAGUNDES, G. S.. Efeito do antigo Lixão do Roger, João Pessoa, Brasil, na qualidade da água subterrânea local. Revista Ambi-Agua, Taubaté, v.4, n.1, 2009. DOI: http://doi:10.4136/ambi-agua.79

BARROS, I. C.. Riscos socioambientais e de saúde: representações sociais dos moradores do entorno do lixão em um município sul baiano. Dissertação (Mestrado em Desenvolvimento Regional e Meio Ambiente) - Universidade Estadual de Santa Cruz, Ilhéus, 2015.

BENDITO, B. P. C.. Diagnóstico da degradação ambiental na área de deposito inadequado de resíduos sólidos de Porto Nacional/TO. Revista Gaia Scientia, João Pessoa, v.11, n.3, p.129-151, 2017. DOI: http://doi.org/10.21707/gs.v11.n03a011

BRAGA, R. L.. Avaliação do gerenciamento de resíduos sólidos gerados em uma feira do Município de Ananindeua/PA. Monografia (Graduação) - Universidade Federal do Pará, Belém, 2015.

BRASIL. Lei n.11.445: Estabelece as diretrizes nacionais para o saneamento básico. Brasília: DOU, 2007.

BRASIL. Lei n.6.938: Dispõe sobre a Política Nacional do Meio Ambiente. Brasília: DOU, 1981.

BRASIL. Lei n.9.605: Dispõe sobre as sanções penais e administrativas derivadas de condutas e atividades lesivas ao meio ambiente. Brasília: DOU, 1998.

BRASIL. Lei n.12.305: Institui a Política Nacional de Resíduos Sólidos. Brasília: DOU, 2010.

BRASIL. Constituição da República Federativa do Brasil, de 5 de outubro de 1988. 11 ed. São Paulo: Atlasm, 1998.

CAIXETA, D. M.. Geração de Energia Elétrica a Partir da Incineração de Lixo Urbano: O Caso de Campo Grande/MS. Monografia (Graduação em Desenvolvimento Sustentável) Universidade de Brasília, Brasília, 2005.

CAVALCANTE, S.; FRANCO, M. F. A.. Profissão perigo: percepção de risco à saúde entre os catadores do Lixão do Jangurussu. Rev. Mal-Estar Subj., Fortaleza, v.7, n.1, p.211231, 2007.

CONAMA. Conselho Nacional do Meio Ambiente. Resolução
CONAMA n.001. Brasília: DOU, 1986.

COSTA, H. S. M.. Desenvolvimento urbano sustentável: uma contradição de termos?. Revista Brasileira de Estudos Urbanos e Regionais, n.2, p.55, 2000. DOI: http://dx.doi.org/10.22296/2317-1529.2000n2p55

FARIA, F. S.. Índice de Qualidade de Aterros de Resíduos Urbanos. Dissertação (Mestrado em Engenharia) Universidade Federal do Rio de Janeiro, Rio de Janeiro, 2002.

GOMES, R. M. V.; CÂMARA, V. M.; SOUZA, D. P. O.. Escolares residentes em área impactada por aterro sanitário e seu conhecimento sobre poluição. Cad. Saúde Colet., Rio de Janeiro, v.23, n.4, p.445-452, 2015.

IBGE. Instituto Brasileiro de Geografia e Estatística. Pesquisa Nacional de Saneamento. Rio de janeiro: IBGE, 2008.

ISMAEL, F. C. M.; LEITE, J. C. A.; SILVA, K. B.. Proposta de um Plano de Recuperação para Área do Lixão em Pombal/PB. Intesa: Informativo Técnico do Semiárido, Pombal, v.7, n.1, p.1-19, 2013.

LEOPOLD, L. B.; CLARKE, F. S.; HANSHAW, B.. A procedure for evaluating environmental impact. Washington: Geological Survey, 1971.

LIRA, J. B. M.. Gestão de Resíduos Sólidos. Recife: IFPE, 2009.

MARQUES, R. F. P. V.. Impactos ambientais da disposição de resíduos sólidos urbanos no solo e na água superficial em três municípios de Minas Gerais. Dissertação (Pósgraduação em recursos hídricos em sistema agrícolas) Universidade Federal de Lavras, Lavras, 2011.

ONE, G. M. C.; ALVES, A. G. M.; MARTINS, P. L.. Catadores de lixo de feiras livres na cidade de Campina Grande/PB. Revista Brasileira de Informações Científicas, v.2, n.4, p.7680, 2011

PEREIRA, S. S.; MELO, J. A. B.. Gestão dos resíduos sólidos urbanos em Campina Grande/PB e seus reflexos socioeconômicos. Revista Brasileira de Gestão e Desenvolvimento Regional, v.4, n.4, p.193-217, Taubaté, 2008.

SIQUEIRA, M. M.; MORAES, M. S.. Saúde coletiva, resíduos sólidos urbanos e os catadores de lixo. Ciência \& Saúde Coletiva, Rio de Janeiro, v.14, n.6, 2009. DOI: http://dx.doi.org/10.1590/S1413-81232009000600018

VAZ, L.; COSTA, B. N.; GUSMÃO, O. S.; AZEVEDO, L. S.. Diagnóstico dos Resíduos sólidos produzidos em uma feira livre: o caso da feira do tomba. Sitientibus, Feira de Santana, n.28, p.145-159, 2003.

YIN, R. K.. Estudo de Caso: Planejamento e Métodos. 2 ed. Porto Alegre: Bookman, 2001.

A CBPC - Companhia Brasileira de Produção Científica (CNPJ: 11.221.422/0001-03) detém os direitos materiais desta publicação. Os direitos referem-se à publicação do trabalho em qualquer parte do mundo, incluindo os direitos às renovações, expansões e disseminações da contribuição, bem como outros direitos subsidiários. Todos os trabalhos publicados eletronicamente poderão posteriormente ser publicados em coletâneas impressas sob coordenação da Sustenere Publishing, da Companhia Brasileira de Produção Científica e seus parceiros autorizados. Os (as) autores (as) preservam os direitos autorais, mas não têm permissão para a publicação da contribuição em outro meio, impresso ou digital, em português ou em tradução. 